\title{
BMJ Open Impact of healthcare access and HIV testing on utilisation of cervical cancer screening among US women at high risk of HIV infection: cross-sectional analysis of 2016 BRFSS data
}

\author{
Dongyu Zhang $(1),{ }^{1}$ Shailesh Advani, ${ }^{1,2}$ Megan Huchko, ${ }^{3}$ Dejana Braithwaite ${ }^{1}$
}

To cite: Zhang D, Advani S, Huchko M, et al. Impact of healthcare access and HIV testing on utilisation of cervical cancer screening among US women at high risk of HIV infection: crosssectional analysis of 2016 BRFSS data. BMJ Open 2020;10:e031823. doi:10.1136/ bmjopen-2019-031823

- Prepublication history and additional material for this paper are available online. To view these files, please visit the journal online (http://dx.doi. org/10.1136/bmjopen-2019031823).

Received 21 May 2019 Revised 12 December 2019 Accepted 13 December 2019

A Check for updates

(c) Author(s) (or their employer(s)) 2020. Re-use permitted under CC BY-NC. No commercial re-use. See rights and permissions. Published by BMJ.

For numbered affiliations see end of article.

Correspondence to Dr Dongyu Zhang; dz216@georgetown.edu

Dr Dejana Braithwaite; db1393@georgetown.edu

\section{ABSTRACT}

Objective Previous studies identified several factors associated with cervical cancer screening. However, many of them used samples from the general population and limited studies focused on women with highrisk health behaviours. We aimed to disentangle the association of cervical cancer screening with healthcare access and HIV testing among women at a high risk of HIV infection.

Design Nationwide cross-sectional survey in the USA.

Setting 2016 Behavioral Risk Factor Surveillance System.

Participants 3448 women with a history of high-risk behaviours associated with HIV infection

Exposure and outcome Clinical check-up, having personal healthcare provider, health coverage and HIV testing history were treated as exposures. Appropriate cervical cancer screening, which was defined according to 2016 US Preventive Services Task Force guideline, was treated as the outcome of interest.

Data analysis Multivariable logistic regression model was performed to evaluate associations of healthcare access and HIV testing with the uptake of cervical cancer screening; adjusted odds ratio (aOR) and 95\% $\mathrm{Cl}$ were reported. We further investigated if educational attainment modified associations identified in the primary multivariable model.

Results A total of 2911 (84.4\%) high-risk women in our sample underwent cervical cancer screening. In the multivariable model, delayed clinical check-up ( $\geq 5$ years ago vs within the past year: a0R: $0.19,95 \% \mathrm{Cl}: 0.14$ to $0.26)$, having no health insurance (aOR: $0.60,95 \% \mathrm{Cl}: 0.46$ to 0.79 ) and no history of HIV testing (no testing vs testing within the past year: aOR: $0.46,95 \% \mathrm{Cl}: 0.35$ to 0.61 ) were inversely associated with cervical cancer screening utilisation.

Conclusion Factors reflecting healthcare access, specifically clinical check-up and health coverage, as well as history of HIV testing were associated with cervical cancer screening in this population-based study of highrisk women. Targeted interventions are warranted to further increase cervical cancer screening among women at high risk of HIV infection.
Strengths and limitations of this study

The large sample size ensures a good power and statistical precision.

- Sensitivity analysis restricted to women without hysterectomy makes the conclusion more robust.

- Screening history was measured by self-report, which is less valid compared with medical record review.

Lack of a clear temporality and causal relationship.

\section{INTRODUCTION}

Cervical cancer is one of the leading gynaecologic cancers impacting women's health in the USA and worldwide. The Surveillance, Epidemiology, and End Results Program has estimated that about 13000 women are diagnosed with cervical cancer annually in the USA. ${ }^{1}$ Cervical cancer screening, which includes both cytology and human papillomavirus (HPV) testing, can effectively prevent cervical cancer when coupled with appropriate follow-up and treatment of preinvasive lesions. ${ }^{2}$ The mortality of cervical cancer was significantly reduced in the USA after the introduction of the Papanicolaou (Pap) test in the 1950s. ${ }^{3}$ Currently, over two-thirds of US adult women undergo cervical cancer screening regularly. ${ }^{4}$

Identification of many barriers and correlates of cervical cancer screening during the last few decades has greatly improved secondary prevention of cervical cancer. It also helped us understand the variation in the patterns of cervical cancer screening across diverse populations defined by demographic and socioeconomic status. ${ }^{5}{ }^{6}$ Moreover, several studies have reported that healthcare-related factors were significantly associated with screening behaviour. For example, health insurance and regular 
primary care physician visits have been shown to be positively associated with cervical cancer screening in previous research. ${ }^{7-9}$ However, there is a paucity of information on how healthcare-related factors may impact cervical cancer screening in US women at a high risk of HIV infection.

Women at a high risk of HIV infection, such as female sex workers (FSW) and intravenous drug users (IDU), can be biologically or socially different from the general population because of their intrinsic high-risk behaviour patterns. ${ }^{10} 11$ For example, a study conducted in China found FSW had a higher prevalence of HPV infection compared with the general population $(61.9 \%$ vs $21.0 \%$, $\mathrm{p}<0.01) .{ }^{12}$ Moreover, women coinfected with HIV and HPV will be more likely to progress to cervical cancer because of the impaired immune surveillance. ${ }^{13} 14$ Therefore, early detection is critical for women with behaviour patterns associated with a high risk of HIV infection.

Although some previous studies have investigated associations between healthcare access and uptake of cervical cancer screening, ${ }^{15}{ }^{16}$ those findings may not be applicable to women at a high risk of HIV. Thus, to disentangle the relationship between healthcare access and cervical cancer screening among these women, we conducted a cross-sectional analysis using the 2016 Behavioral Risk Factor Surveillance System (BRFSS) data. In addition, these high-risk women may seek HIV testing services; thus, we treated HIV testing as a special indicator reflecting health services utilisation and included it in the analysis as well.

\section{METHODS \\ BRFSS}

BRFSS is a cross-sectional telephone survey initiated in 1984 across the USA which collects resident adults' ( $\geq 18$ years) self-reported information about health-related behaviours, overall health conditions and use of medical services. Questions in BRFSS received technical review, cognitive testing and field testing before being added to the questionnaire. The BRFSS covers information from all 50 states, the District of Columbia, Puerto Rico, the US Virgin Islands, Guam, American Samoa and Palau. We used data derived from 2016 BRFSS for current analysis. In 2016, computer-assisted telephone interview systems (in both English and Spanish) were used in most of the interviews via landlines or cell phones. In states using in-house surveys, interviewers had received additional training on the BRFSS questionnaire and procedures before the interviews. ${ }^{1718}$

\section{Study population}

Based on questions asked in BRFSS, women were treated as being at a high risk of HIV infection if they had one or more of the following behaviours within past year: (1) used intravenous drug, (2) received treatment for a sexually transmitted or venereal disease, (3) gave or received money/drugs in exchange for sex, (4) had anal sex without condom or (5) had four or more sex partners. ${ }^{17} 18$ To protect participants' privacy, respondents did not need to report the specific type of behaviour they did. The 2016 BRFSS reported age measured at interview as a categorical variable with certain time intervals; specifically, '18-24 years' and '59-65 years' were treated as individual categories. Thus, we restricted the age range as 25-64 in order to make it lie within the range suggested by US Preventive Services Task Force (USPSTF). For current analysis, women at a high risk of HIV infection who were between 25 and 64 years without missing value of cervical cancer screening, exposure of interest and other covariates were included, which yielded a total of 3448 women.

\section{Patient and public involvement}

Participants were selected as described above and were not involved in the design of this study.

\section{Exposure and outcome of interest}

Four exposures of interest were included in our analysis. Routine clinical check-up, personal healthcare provider and health coverage were used to represent access to healthcare in the 2016 BRFSS. The question 'About how long has it been since you last visited a doctor for a routine check-up?' was used to measure history of a general physical exam, not an exam for a specific injury, illness or condition. We categorised history of check-up based on time elapsed since last check-up $(<1,1-<2,2-<5$ and $\geq 5$ years ago). Personal healthcare provider was measured by question 'Do you have one person you think of as your personal doctor or healthcare provider?' We categorised this variable as a binary variable (had vs had no provider). Women were treated as having health coverage if they had any type of health insurance, prepaid plans (eg, HMO), government plans (eg, Medicare) or Indian Health Service. The Centers for Disease Control and Prevention (CDC) recommended people at a high risk of HIV infection should undergo HIV testing at least once every year. ${ }^{19}$ Thus, HIV testing was treated as a categorical variable based on the self-reported information on testing history and time elapsed since the test (test within last year, test $>1$ year ago and had no test).

The 2016 BRFSS measured uptake of Pap test, HPV test and time elapsed since last test. ${ }^{17} 18$ The following questions were used to measure cervical cancer screening utilisation: (1) 'A Pap test is a test for cancer of the cervix. Have you ever had a Pap test?' (2) 'How long has it been since you had your last Pap test?' (3) 'An HPV test is sometimes given with the Pap test for cervical cancer screening. Have you ever had an HPV test?' and (4) 'How long has it been since you had your last HPV test?' According to the USPSTF screening guidelines at 2016, women with one of the following screening histories were treated as the outcome of interest: (1) 21-65 years and had a Pap test within last 3 years and (2) 30-65 years and had a Pap test within last 5 years combined with an HPV test. ${ }^{20}$ 


\section{Other covariates}

Age at interview was recategorised by 10 -year intervals (25-34, 35-44, 45-54 and 55-64 years). Self-reported race was categorised as white, black and other. Educational background was classified as high school or less, attended college or technical school or graduated from college or technical school. Since previous research reported married people had a stronger feeling of responsibility and obligation to their spouses, screening behaviours could be different between married and unmarried people ${ }^{21}$; in our study, women self-reported as never married, divorced, widowed or separated were considered as unmarried. Four lifestyle factors were considered in analysis because they could be indicators of health awareness and associated with health-seeking behaviours and cervical cancer screening. ${ }^{22}{ }^{23}$ Specifically, based on the structure of questionnaire, these factors were categorised and defined as follows: (1) obesity was defined as having a body mass index $(\mathrm{BMI}) \geq 30 \mathrm{~kg} / \mathrm{m}^{2}$, (2) regular physical exercise was defined as having physical activities or exercises (eg, running, callisthenics, golf, gardening or walking for exercise) during past month, ${ }^{24}$ (3) heavy drinker was defined as having more than seven drinks per week during the past month ${ }^{25}$ and (4) selfreported smoking status was treated as never, current and former smoker based on self-reported information. Previous research indicated chronic health problems and overall health condition could be associated with health services utilisation and be barriers to cervical cancer screening. ${ }^{26} 27$ The 2016 BRFSS measured eight types of common illnesses which were considered in the analysis: asthma, chronic obstructive pulmonary disease, diabetes mellitus, myocardial infarction, coronary heart disease, stroke, chronic kidney disease and arthritis. Participants self-reported their perceived health condition and it was categorised as a binary variable (poor/fair vs good/very good/excellent). Selection of covariates was based on a priori knowledge.

\section{Statistical analysis}

Because we investigated a small proportion of women $(<1 \%)$ in the 2016 BRFSS, who could be demographically different from the general population, we used an unweighted analysis to avert bias and imprecision. First, we descriptively summarised the data by reporting the number of observations and percentage for each covariate in overall sample and subpopulation defined by cervical cancer screening utilisation. $\chi^{2}$ tests were used to investigate if distributions of these covariates differed by screening utilisation. We also reported the number of observations and distributions of clinical check-up, personal healthcare provider, health coverage and HIV testing for study population. Point estimates and 95\% CIs of cervical cancer screening rate were reported for these four factors. Unadjusted logistic regressions were used to calculate crude odds ratio and $95 \%$ CI of clinical check-up, personal healthcare provider, health coverage and HIV testing separately. A multivariable logistic regression model included these four factors simultaneously and adjusted for age, race, education, marital status, obesity, physical activity, alcohol consumption, smoking status, comorbidity and overall health condition. Adjusted odds ratios (aORs) and 95\% CIs of clinical check-up, personal healthcare provider, health coverage and HIV testing were calculated from the multivariable model. Subgroup analysis by education level (less than college vs at or above college) was conducted because education could impact intention of screening and be a potential effect modifier. ${ }^{24}{ }^{28}{ }^{29}$ We generated interaction terms between these four factors and education which were added into the multivariable logistic regression model, and Wald tests were used to investigate if there were significant interactions. A sensitivity analysis was conducted by analysing women who confirmed they did not undergo hysterectomy to examine if association patterns changed significantly compared with the primary multivariable model. For current analysis, two-sided $p$ values $<0.05$ were considered to be statistically significant. All statistical analyses were conducted using Stata V.15.0 (StataCorp, LLP, College Station, Texas, USA).

\section{RESULTS}

A total of 3448 women meeting our selection criteria were included for the analysis (figure 1). Over $80 \%$ of the study population $(\mathrm{n}=2911,84.4 \%)$ underwent appropriate cervical cancer screening. Table 1 presents the descriptive summary of sociodemographic and healthrelated characteristics of these women. Overall, over a half were between age 35 and 64 years $(57.2 \%)$ or white women $(74.5 \%)$. Women with appropriate cervical cancer screening tended to be younger, have higher education background, be more likely to have regular physical exercise, be non-current smokers and have fewer comorbidities and better overall health status ( $p$ values $<0.05$ ). We did not find evidence suggesting marital status, obesity and alcohol consumption were distributed differently by screening history.

Over two-thirds $(68.1 \%)$ of these women had their last clinical check-up within the past year and $8.7 \%$ had the last checkup $\geq 5$ years ago. Over three-fourths $(77.5 \%)$ of study participants had personal healthcare providers and most people had health coverage (87.4\%). In terms of HIV testing, $70.1 \%$ of these women reported having a history of testing; specifically, $34.9 \%$ had the test over 1 year ago and $35.2 \%$ had the test within last year (table 2). Cervical cancer screening rate was higher in women having a recent clinical check-up (checkup <1 year ago: $88.9 \%$ vs checkup $\geq 5$ years ago: $58.1 \%$ ), having personal healthcare provider (yes: $86.4 \%$ vs no: $77.7 \%$ ), owning health coverage (yes: $86.5 \%$ vs no: $70.3 \%$ ) or undergoing HIV testing (test within last year: $90.6 \%$ vs no test: $77.9 \%$ ). The multivariable model suggested delayed clinical check-up ( $\geq 5$ years ago vs within last year: aOR: $0.19,95 \%$ CI: 0.14 to 0.26 ), having no coverage (aOR: $0.60,95 \% \mathrm{CI}: 0.46$ to 0.79 ) and not undergoing HIV testing (aOR: 0.46, 
486,303 participants in 2016 BRFSS

Male participants $(n=210,672)$

Women not at high risk of HIV infection $(n=268,962)$

Age $<25$ or $>64(n=2,019)$

No information about cervical cancer screening $(n=119)$

Had missing value in any of the exposures and covariates

$(n=1,083)$

Final sample for analysis $(\mathrm{N}=3,448)$

Figure 1 Flowchart of selection of study population. A total of 3448 women at a high risk of HIV infection were included for current study. BRFSS, Behavioral Risk Factor Surveillance System.

$95 \%$ CI: 0.35 to 0.61 , compared with test within last year) were inversely associated with cervical cancer screening. However, having a personal healthcare provider was not significantly associated with screening (table 2).

A significant interaction was observed between clinical check-up and education level ( $p$ interaction=0.04). Particularly, effect measures of delayed clinical check-up were more substantial among women with a higher education level (1-<2 years ago: aOR: $0.51,95 \%$ CI: 0.29 to 0.89 ; $2-<5$ years ago: aOR: $0.19,95 \%$ CI: 0.10 to 0.33 ; $\geq 5$ years ago: aOR: 0.22 , $95 \%$ CI: 0.11 to 0.42 , compared with $<1$ year ago). We did not observe evidence suggesting significant interactions for personal healthcare provider, health coverage and HIV testing (table 3).

We observed inverse and significant effect measures of clinical check-up, health coverage and HIV testing in sensitivity analysis as well $(n=2570)$. The association patterns were similar to those observed in the primary multivariable model (online supplementary table 1).

\section{DISCUSSION}

Overall, we observed that delayed clinical check-up, living without health coverage and lack of HIV testing were inversely associated with cervical cancer screening among women at a high risk of HIV infection. Having a personal healthcare provider was not independently associated with screening behaviour. Furthermore, we found that the negative impact of delayed clinical check-up was more substantial among women with higher educational background.

The wide definition of high-risk behaviour in BRFSS makes our study population socially diverse and consists of sexually active women (eg, FSW), IDU and people living with HIV. Some studies focusing on such population reported similar outcomes as did ours. An epidemiology study $(n=1490)$ conducted in the USA found HIV-infected women living with Medicaid were less likely to be underscreened for cervical cancer (OR: 0.63, $95 \%$ CI: 0.41 to 0.96 , compared with uninsured women). ${ }^{30}$ 
Table 1 Study characteristics of women at high risk of HIV infection-2016 BRFSS

\begin{tabular}{|c|c|c|c|c|}
\hline & $\begin{array}{l}\text { Overall } \\
(n=3448)\end{array}$ & $\begin{array}{l}\text { Had no cervical } \\
\text { cancer screening } \\
(n=53715.6 \%)\end{array}$ & $\begin{array}{l}\text { Had cervical cancer } \\
\text { screening } \\
(n=291184.4 \%)\end{array}$ & \\
\hline Study characteristics & n (\%) & n (\%) & n (\%) & $P$ value \\
\hline \multicolumn{5}{|l|}{ Age at interview (years) } \\
\hline $25-34$ & $1477(42.8)$ & $184(34.3)$ & $1293(44.4)$ & $<0.01$ \\
\hline $35-44$ & $913(26.5)$ & $128(23.8)$ & $785(27.0)$ & \\
\hline $55-64$ & $400(11.6)$ & $107(19.9)$ & $293(10.1)$ & \\
\hline \multicolumn{5}{|l|}{ Race } \\
\hline White & $2567(74.5)$ & $411(76.5)$ & $2156(74.1)$ & 0.06 \\
\hline Black & $583(16.9)$ & $73(13.6)$ & $510(17.5)$ & \\
\hline Other & $298(8.6)$ & $53(9.9)$ & $245(8.4)$ & \\
\hline Graduated from college & $1263(36.6)$ & $121(22.5)$ & $1142(39.2)$ & \\
\hline \multicolumn{5}{|l|}{ Marital status* } \\
\hline Unmarried & $2120(61.5)$ & $331(61.6)$ & 1789 (61.5) & 0.94 \\
\hline Married & $1328(38.5)$ & $206(38.4)$ & $1122(38.5)$ & \\
\hline \multicolumn{5}{|l|}{ Obesity (BMI $\geq 30 \mathrm{~kg} / \mathrm{m}^{2}$ ) } \\
\hline No & $2164(62.8)$ & $332(61.8)$ & 1832 (62.9) & 0.63 \\
\hline Yes & $1284(37.2)$ & 205 (38.2) & $1079(37.1)$ & \\
\hline \multicolumn{5}{|l|}{ Regular physical exercise } \\
\hline No & $819(23.8)$ & $186(34.6)$ & $633(21.8)$ & $<0.01$ \\
\hline Current smoker & $1229(35.6)$ & $270(50.3)$ & 959 (32.9) & \\
\hline Former smoker & $678(19.7)$ & $78(14.5)$ & $600(20.6)$ & \\
\hline \multicolumn{5}{|l|}{ Number of comorbidities $†$} \\
\hline 0 & $1845(53.5)$ & $258(48.0)$ & $1587(54.5)$ & $<0.01$ \\
\hline 1 & $949(27.5)$ & $147(27.4)$ & $802(27.6)$ & \\
\hline$\geq 2$ & $654(19.0)$ & $132(24.6)$ & $522(17.9)$ & \\
\hline \multicolumn{5}{|l|}{ Overall health condition } \\
\hline Fair or poor & $784(22.7)$ & $176(32.8)$ & $608(20.9)$ & $<0.01$ \\
\hline Good, very good or excellent & $2664(77.3)$ & $361(67.2)$ & $2303(79.1)$ & \\
\hline
\end{tabular}

Women having cervical cancer screening were defined as follows: (1) women aged between 21 and 65 having a Pap test within the last 3 years, (2) women aged between 30 and 65 having a Pap test within the last 5 years accompanied by an HPV test.

*Women who were never married, divorced, widowed or separated were treated as not married. Married women or unmarried couples were treated as married.

†Eight comorbidities were considered: asthma, COPD, diabetes mellitus, stroke, myocardial infarction, coronary heart disease, chronic kidney disease and arthritis.

łp value was calculated by $\chi^{2}$ test.

BMI, body mass index; BRFSS, Behavioral Risk Factor Surveillance System.

A study of IDU conducted in Canada $(\mathrm{n}=297)$ reported that visiting a family physician in the prior 6 months (OR: $3.10,95 \%$ CI: 1.58 to 6.07 ) was positively associated with cervical cancer screening. ${ }^{31}$ Duff $e$ t $a l^{32}$ studied 611 FSW in Canada and found barriers to accessing healthcare service was inversely associated with cervical cancer 
Table 2 Associations of healthcare access and HIV test with cervical cancer screening in women at a high risk of HIV infection

\begin{tabular}{|c|c|c|c|c|}
\hline Factors & $\begin{array}{l}\text { Overall distribution } \\
\mathrm{n}(\%)\end{array}$ & $\begin{array}{l}\text { Cervical cancer screening } \\
\text { percentage and } 95 \% \mathrm{Cl}\end{array}$ & $\begin{array}{l}\text { cOR and } 95 \% \mathrm{Cl} \\
(\mathrm{n}=3448)\end{array}$ & $\begin{array}{l}\text { aOR and } 95 \% \mathrm{Cl} \dagger \\
(\mathrm{n}=3448)\end{array}$ \\
\hline \multicolumn{5}{|l|}{ Last clinical check-up* } \\
\hline$<1$ year ago (REF) & $2347(68.1)$ & 88.9 (87.6 to 90.1$)$ & 1 & 1 \\
\hline $1-<2$ years ago & $502(14.6)$ & 86.3 (83.0 to 89.0$)$ & 0.78 (0.59 to 1.04$)$ & 0.74 (0.54 to 1.00$)$ \\
\hline $2-<5$ years ago & $298(8.6)$ & 72.5 (67.1 to 77.3$)$ & 0.33 (0.25 to 0.44$)$ & 0.31 (0.23 to 0.43$)$ \\
\hline$\geq 5$ years ago & $301(8.7)$ & 58.1 (52.5 to 63.6) & $0.17(0.13$ to 0.23$)$ & 0.19 (0.14 to 0.26$)$ \\
\hline \multicolumn{5}{|c|}{ Had personal healthcare provider } \\
\hline Yes (REF) & $2671(77.5)$ & 86.4 (85.0 to 87.6$)$ & 1 & 1 \\
\hline No & 777 (22.5) & 77.7 (74.7 to 80.5$)$ & 0.55 (0.45 to 0.67$)$ & 0.93 (0.72 to 1.20$)$ \\
\hline \multicolumn{5}{|l|}{ Had healthcare coverage } \\
\hline Yes (REF) & $3013(87.4)$ & 86.5 (85.2 to 87.6$)$ & 1 & 1 \\
\hline No & $435(12.6)$ & 70.3 (65.9 to 74.5$)$ & 0.37 (0.29 to 0.47$)$ & 0.60 (0.46 to 0.79$)$ \\
\hline \multicolumn{5}{|l|}{ Had HIV test } \\
\hline $\begin{array}{l}\text { Had test within last year } \\
\text { (REF) }\end{array}$ & 1215 (35.2) & 90.6 (88.8 to 92.1$)$ & 1 & 1 \\
\hline Had test over 1 year ago & $1202(34.9)$ & 83.8 (81.6 to 85.8$)$ & 0.53 (0.42 to 0.68$)$ & 0.64 (0.49 to 0.84$)$ \\
\hline Had no test & 1031 (29.9) & 77.9 (75.2 to 80.3$)$ & 0.36 (0.29 to 0.46$)$ & 0.46 (0.35 to 0.61$)$ \\
\hline
\end{tabular}

Women having cervical cancer screening were defined as follows: (1) women aged between 21 and 65 having a Pap test within the last 3 years, (2) women aged between 30 and 65 having a Pap test within the last 5 years accompanied by an HPV test.

${ }^{\star}$ The check-up specifically referred to a general physical exam, not an exam for a specific injury, illness, or condition. †The multivariable logistic regression model included the four factors in table simultaneously and adjusted for age, race, education, marital status, obesity, physical activity, alcohol consumption, smoking status, comorbidity and overall health condition. aOR, adjusted OR;cOR, crude OR; HPV, human papillomavirus; Pap, Papanicolaou.

screening (OR: $0.81,95 \%$ CI: 0.65 to 1.00 ). However, these studies have some methodological limitations. For example, these studies have smaller sample sizes, which can induce random error and compromise representativeness. In addition, lifestyle factors (eg, obesity, smoking and physical activity) were not sufficiently considered in statistical analyses of these studies. Since lifestyle factors have been found to be associated with health services utilisation and cervical cancer screening, ${ }^{23} 2433$ analysis without adjustment for these factors can lead to a substantial bias. These limitations were considered in our study and resolved by using a larger population-based sample and more appropriate statistical methods such as adjustment for multiple lifestyle factors.

Several mechanisms may explain outcomes regarding the associations of clinical check-up, health coverage and HIV testing. Delayed clinical check-up can impede appropriate patient-physician communication and obstruct acquisition of medical knowledge related to cervical cancer prevention, which can finally impede the uptake of screening. For example, an epidemiologic study of 352 Asian women in the USA found that receiving physicians' recommendation was associated with a sevenfold higher likelihood of undergoing cervical cancer screening. ${ }^{34}$ Lack of healthcare coverage increases financial stress and leads to lower intention to undergo cancer screening, ${ }^{35-38}$ which can hinder screening utilisation. Because of the impaired immune homeostasis,
HIV-infected women are at a higher risk of HPV infection and cervical cancer development. ${ }^{39}$ A meta-analysis of 38 studies reported that HIV-infected women had a higher risk of HPV infection (risk ratio (RR): 2.64, 95\% CI: 2.04 to 3.42 ) and cervical cancer incidence (RR: $4.10,95 \%$ CI: 2.30 to 6.60). During the HIV testing procedure, participants can have an opportunity to obtain such knowledge from clinicians, increase the awareness of HIV-related harms and consider undergoing cervical cancer screening. The associations between delayed clinical check-up and cervical cancer screening are stronger among highly educated women, but the underlying reason remains unclear. Based on an epidemiologic perspective, we hypothesised that the obstructive effects of lower educational level on screening would be much stronger than delayed clinical check-up, thus the effect measures for delayed check-up should be less substantial among women with lower educational level. Meanwhile, the heterogeneous association pattern by education suggests shortening routine clinical check-up intervals can better improve screening utilisation among highly educated women.

Our study design and analysis has some strengths. For example, we had a good power due to the large sample size. In addition, we compared estimates in sensitivity analysis with primary analysis, which made the associations in primary analysis more robust. However, the research still has some limitations. First, all of the factors 
Table 3 Associations of healthcare access and HIV test with cervical cancer screening in subgroups defined by education

\begin{tabular}{|c|c|c|c|c|c|}
\hline \multirow[b]{2}{*}{ Factors } & \multicolumn{2}{|c|}{ Less than college level $(n=2185)$} & \multicolumn{2}{|c|}{ At or above college level $(n=1263)$} & \multirow[b]{2}{*}{$\mathbf{P}$ interaction $\dagger$} \\
\hline & n (\%) & aOR and $95 \% \mathrm{Cl}$ & n (\%) & aOR and $95 \% \mathrm{Cl}$ & \\
\hline \multicolumn{6}{|l|}{ Last clinical check-up* } \\
\hline $1-<2$ years ago & $297(13.6)$ & 0.86 (0.60 to 1.24$)$ & 205 (16.2) & 0.51 (0.29 to 0.89$)$ & \\
\hline $2-<5$ years ago & $199(9.1)$ & 0.39 (0.27 to 0.57$)$ & $99(7.8)$ & 0.19 (0.10 to 0.33$)$ & \\
\hline \multicolumn{6}{|l|}{ Had personal healthcare provider } \\
\hline Yes (REF) & $1661(76.0)$ & 1 & $1010(80.0)$ & 1 & 0.47 \\
\hline No & $524(24.0)$ & 0.98 (0.73 to 1.32$)$ & $253(20.0)$ & 0.78 (0.48 to 1.27$)$ & \\
\hline \multicolumn{6}{|l|}{ Had healthcare coverage } \\
\hline Yes (REF) & $1835(84.0)$ & 1 & 1178 (93.3) & 1 & 0.84 \\
\hline Had test over 1 year ago & $731(33.5)$ & 0.62 (0.45 to 0.84$)$ & $471(37.3)$ & $0.73(0.41$ to 1.31$)$ & \\
\hline Had no test & $636(29.1)$ & 0.48 (0.35 to 0.66$)$ & $395(31.3)$ & $0.43(0.24$ to 0.77$)$ & \\
\hline
\end{tabular}

Multivariable logistic regression model included the four factors in table simultaneously and adjusted for age, race, marital status, obesity, physical activity, alcohol consumption, smoking status, comorbidity and overall health condition.

*The check-up specifically referred to a general physical exam, not an exam for a specific injury, illness or condition. †Wald test was used to investigate interaction between factors and education in relation to cervical cancer screening. aOR, adjusted OR.

in analysis were measured by self-report approach, which could be less accurate compared with medical record review. Second, we cannot examine whether the association identified is causal because BRFSS is a crosssectional survey and cannot establish clear temporality. Third, the BRFSS did not provide detailed information related to high-risk behaviours, which makes it impossible to conduct subgroup analysis by specific behaviour patterns and examine internal heterogeneity in this study population (eg, to compare FSW vs IDU). Fourth, since BRFSS is not specifically designed as a survey for cervical cancer prevention and lacks detailed descriptions of screening techniques, women without relevant knowledge regarding cervical cancer might not have answered the question accurately. Fifth, because the study population consisted of predominantly white and insured women, the sample may be less representative of women at increased risk of HIV infection or cervical cancer in the USA. ${ }^{40}$ Finally, current HIV infection status and antiretroviral therapy (ART) use can be very important correlates of cervical cancer screening among women at a high risk of HIV infection. ${ }^{30}$ However, the whole 2016 BRFSS sample only contains a small proportion of participants who self-reported as HIV-infected (31 out of 486 303) and there is no question asking for ART use in BRFSS.

The implication of our study is that health practitioners can identify women at a high risk of HIV infection, who are less likely to undergo cervical cancer screening and provide targeted interventions such as risk-based screening. For example, communication with
FSW without history of HIV testing about the knowledge of HIV and cervical cancer could help elevate awareness and perceived risk of cervical cancer, which may increase the likelihood of screening utilisation.

In conclusion, our study found delayed clinical check-up, having no health coverage and lack of HIV testing may be potential barriers to cervical cancer screening among women at a high risk of HIV infection. This evidence can help health practitioners establish a more targeted risk-based cervical cancer screening intervention. Future research should establish prospective cohort studies, which have clear temporality, to further disentangle the association of access to healthcare and HIV testing with cervical cancer screening.

\section{Author affiliations}

${ }^{1}$ Department of Oncology, Georgetown University School of Medicine, Washington, District of Columbia, USA

${ }^{2}$ Social Behavioral Research Branch, National Institutes of Health, Bethesda, Maryland, USA

${ }^{3}$ Department of Obstetrics and Gynecology, Duke Global Health Institute, Durham, North Carolina, USA

Acknowledgements The authors appreciate research staff participating in BRFSS data collection, management and dissemination.

Contributors DZ and DB helped in the research question development. DZ performed the data acquisition. Analytical plan development was done by $\mathrm{DZ}$ and DB. DZ performed the data analysis. DZ, SA, MH and DB helped in the results interpretation. Drafting manuscript was done by $\mathrm{DZ}$ and manuscript revision was done by DZ, SA, MH and DB. All authors reviewed and commented on the manuscript. 
Funding This project was supported by an the Global Health Initiative, Georgetown University

Competing interests None declared.

Patient consent for publication Not required.

Ethics approval BRFSS is a publicly available de-identified dataset and does not require IRB approval.

Provenance and peer review Not commissioned; externally peer reviewed.

Data availability statement Data are available in a public, open access repository.

Open access This is an open access article distributed in accordance with the Creative Commons Attribution Non Commercial (CC BY-NC 4.0) license, which permits others to distribute, remix, adapt, build upon this work non-commercially, and license their derivative works on different terms, provided the original work is properly cited, appropriate credit is given, any changes made indicated, and the use is non-commercial. See: http://creativecommons.org/licenses/by-nc/4.0/.

ORCID iD

Dongyu Zhang http://orcid.org/0000-0002-3545-1771

\section{REFERENCES}

1 Cancer STAT facts: cervical cancer. Available: https://seer.cancer gov/statfacts/html/cervix.html [Accessed Last accessed 27th Oct 2018].

2 Brown AJ, Trimble CL. New technologies for cervical cancer screening. Best Pract Res Clin Obstet Gynaecol 2012;26:233-42.

3 Devesa SS, Young JL, Brinton LA, et al. Recent trends in cervix uteri cancer. Cancer 1989;64:2184-90.

4 Zhang D, Sun X. Pap testing in the USA and potential association with HPV vaccination: a cross-sectional analysis of the BRFSS data (2007-2016). J Gen Intern Med 2019;34:17-19.

5 Selvin E, Brett KM. Breast and cervical cancer screening: sociodemographic predictors among white, black, and Hispanic women. Am J Public Health 2003;93:618-23.

6 Austin LT, Ahmad F, McNally M-J, et al. Breast and cervical cancer screening in Hispanic women: a literature review using the health belief model. Women's Health Issues 2002;12:122-8.

7 Kaso M, Takahashi Y, Nakayama T. Factors related to cervical cancer screening among women of childrearing age: a cross-sectional study of a nationally representative sample in Japan. Int J Clin Oncol 2019;24:313-322.

8 Zhao G, Okoro CA, Li J, et al. Health insurance status and clinical cancer screenings among U.S. adults. Am J Prev Med 2018;54:e11-19.

9 Rodríguez MA, Ward LM, Pérez-Stable EJ. Breast and cervical cancer screening: impact of health insurance status, ethnicity, and nativity of Latinas. Ann Fam Med 2005;3:235-41.

10 Injection drug use and HIV risk. Available: https://www.cdc.gov/hiv/ risk/idu.html [Accessed Last accessed 28th Oct 2018].

11 Paz-Bailey G, Noble M, Salo K, et al. Prevalence of HIV among U.S. female sex workers: systematic review and meta-analysis. AIDS Behav 2016;20:2318-31.

12 Jia $\mathrm{H}$, Wang $\mathrm{X}$, Long $\mathrm{Z}$, et al. Human papillomavirus infection and cervical dysplasia in female sex workers in northeast China: an observational study. BMC Public Health 2015;15:695.

13 Abraham AG, D'Souza G, Jing Y, et al. Invasive cervical cancer risk among HIV-infected women: a North American multicohort collaboration prospective study. J Acquir Immune Defic Syndr 2013;62:405-13.

14 Ferenczy A, Coutlée F, Franco E, et al. Human papillomavirus and HIV coinfection and the risk of neoplasias of the lower genital tract: a review of recent developments. CMAJ 2003;169:431-4.

15 Cerigo H, Coutlée F, Franco EL, et al. Factors associated with cervical cancer screening uptake among Inuit women in Nunavik, Quebec, Canada. BMC Public Health 2013;13:438.

16 Ncube B, Bey A, Knight J, et al. Factors associated with the uptake of cervical cancer screening among women in Portland, Jamaica. $N$ Am J Med Sci 2015;7:104-13.
17 Centers for Disease Control and Prevention (CDC). Behavioral risk factor surveillance system survey questionnaire. Atlanta, Georgia: U.S. Department of Health and Human Services, Centers for Disease Control and Prevention, 2018.

18 Centers for Disease Control and Prevention (CDC). Behavioral risk factor surveillance system survey data. Atlanta, Georgia: U.S. Department of Health and Human Services, Centers for Disease Control and Prevention, 2018.

19 HIV testing. Available: https://www.cdc.gov/hiv/testing/index.html [Accessed Last accessed 25th Jan 2019].

20 Sabatino SA, White MC, Thompson TD, et al. Cancer screening test use - United States, 2013. MMWR Morb Mortal Wkly Rep 2015;64:464-8

21 Van Jaarsveld CHM, Miles A, Edwards R, et al. Marriage and cancer prevention: does marital status and inviting both spouses together influence colorectal cancer screening participation? J Med Screen 2006;13:172-6.

22 Miles-Richardson S, Allen S, Claridy MD, et al. Factors associated with self-reported cervical cancer screening among women aged 18 years and older in the United States. J Community Health 2017;42:72-7.

23 Richard A, Rohrmann S, Schmid SM, et al. Lifestyle and healthrelated predictors of cervical cancer screening attendance in a Swiss population-based study. Cancer Epidemiol 2015;39:870-6.

24 Zhang D, Zhang C, Sun X, et al. Bmi, physical inactivity, and Pap test use in Asian women in the U.S. Am J Prev Med 2019;56:e85-94.

25 Fleming MF. Screening and brief intervention in primary care settings. Alcohol Res Health 2004;28:57-62

26 Kiefe Cl, Funkhouser E, Fouad MN, et al. Chronic disease as a barrier to breast and cervical cancer screening. J Gen Intern Med 1998;13:357-65.

27 Bazargan M, Bazargan SH, Farooq M, et al. Correlates of cervical cancer screening among underserved Hispanic and AfricanAmerican women. Prev Med 2004;39:465-73.

28 Shaikh BT. Understanding social determinants of health seeking behaviours, providing a rational framework for health policy and systems development. J Pak Med Assoc 2008;58:33-6.

29 Zhang Q, Lauderdale D, Mou S, et al. Socioeconomic disparity in healthcare-seeking behavior among Chinese women with genitourinary symptoms. J Womens Health 2009;18:1833-9.

30 Barnes A, Betts AC, Borton EK, et al. Cervical cancer screening among HIV-infected women in an urban, United States safety-net healthcare system. AIDS 2018;32:1861-70.

31 McKnight B, McKnight I, Kerr T, et al. Prevalence and correlates of cervical cancer screening among injection drug users. J Obstet Gynaecol Can 2006;28:695-9.

32 Duff P, Ogilvie G, Shoveller J, et al. Barriers to cervical screening among sex workers in Vancouver. Am J Public Health 2016;106:366-73.

33 Maruthur NM, Bolen SD, Brancati FL, et al. The association of obesity and cervical cancer screening: a systematic review and meta-analysis. Obesity 2009;17:375-81.

34 Taylor VM, Yasui Y, Burke N, et al. Pap testing adherence among Vietnamese American women. Cancer Epidemiol Biomarkers Prev 2004;13:613-9.

35 Jennings-Dozier K. Predicting intentions to obtain a Pap smear among African American and Latina women: testing the theory of planned behavior. Nurs Res 1999;48:198-205.

36 Nguyen TT, McPhee SJ, Nguyen T, et al. Predictors of cervical Pap smear screening awareness, intention, and receipt among Vietnamese-American women. Am J Prev Med 2002;23:207-14.

37 Ford ME, Vernon SW, Havstad SL, et al. Factors influencing behavioral intention regarding prostate cancer screening among older African-American men. J Natl Med Assoc 2006;98:505-14.

38 Anderson M, Dobkin C, Gross T. The effect of health insurance coverage on the use of medical services. Am Econ J Econ Policy 2012:4:1-27.

39 Ghebre RG, Grover S, Xu MJ, et al. Cervical cancer control in HIV-infected women: past, present and future. Gynecol Oncol Rep 2017;21:101-8.

40 Ortiz AP, Engels EA, Nogueras-González GM, et al. Disparities in human papillomavirus-related cancer incidence and survival among human immunodeficiency virus-infected Hispanics living in the United States. Cancer 2018;124:4520-8. 